\title{
Prediction of Air Permeability in Hybrid Nanocomposite Based on Bromobutyl/Epichlorohydrin Rubber Blends as Tire Inner Liner Using Finite Element Method
}

\author{
Kumar Sankaran ${ }^{1}$, Kaushik Mukherjee ${ }^{2}$, Partheban Manoharan ${ }^{1}$, Golok B. Nando ${ }^{1}$ and Santanu Chattopadhyay ${ }^{1 *}$ \\ 1. Rubber Technology Centre, Indian Institute of Technology, Kharagpur 721302, India \\ 2. Department of Mechanical Engineering, Indian Institute of Technology, Kharagpur 721302, India
}

\begin{abstract}
In the present work, a novel attempt has been proposed to simulate air permeability in tire inner liner based on bromobutyl (BIIR)/epichlorohydrin (CO) rubber blend nanocomposite. ANSYS ${ }^{\circledR}$ software has been adopted for FEM analysis. It provides an essential insight into the prediction of air permeability using thermal/gas analogy. The simulated results are compared and successfully validated with the field tire results. It is found that the hybrid nanocomposite offers a substantial reduction in air permeability as compared to the standard inner liner compound. It signifies the impact of the nanostructures on enhancing the gas barrier of the tire inner liner with time. The prediction gives a possibility to improve proactively the quality of inner liner compound developed.
\end{abstract}

Key words: Rubber, hybrid nanostructures, FEM, thermal analogy, air permeability.

\section{Introduction}

Real-time investigation of air permeability of the tire inner liner is a tedious process. However, the prediction of air permeability of tire inner liner with time is necessary as it affects the durability and performance of the tire. A successful attempt has been made to simulate and predict the air permeability of rubber nanocomposite for tire inner liner materials. Among various material modeling and simulation methods, FEM is preferred as it can provide accurate estimates for a broad range of assumptions. FEM is a general numerical method for obtaining approximate solutions to boundary-value based problems including time-dependent processes. FEM employs preprocessed mesh generation by configuring nodal points, which enables the model to capture fully and analyze the spatial discretization of highly inhomogeneous materials. FEM also considers solving complex, nonlinear elastic problems for analysis. It has been widely used in mechanical, chemical, and

*Corresponding author: Santanu Chattopadhyay, Dr., research field: rubber technology. elastomeric systems. FEM can be used for numerical computation of bulk properties based on the geometry, properties, and volume fraction of constituent phases $[1,2]$. FEM-based micromechanics have been used extensively for the prediction of mechanical properties of polymer nanocomposites [3]. Elastic properties of the nanocomposites filled with carbon nanotubes (CNTs) have been computed effectively. It has been done by equating asymptotic expansion homogenization method available with control volume FEM [4]. Albeit, various software packages and open source codes incorporates FEM (e.g., ABAQUS, ANSYS, Palmyra and OOF) to evaluate the mechanical properties of polymer composites $[5,6]$, ANSYS $^{\circledR}$ has been employed for FEM. It is due to the simplicity in approach and easy preprocessing for problem definition. Few attempts have recently been made to solve problems on polymer-based nanocomposites by applying FEM [7, 8]. Tribological behavior of ENR based nanocomposites were analyzed using FEM [9]. Further, a novel modeling of diffusion in polymer-clay nanocomposites by 
subjecting TEM photomicrographs of nanocomposites for finite element analysis was reported [10]. In spite of not considering the possible effects of size on diffusing molecules, they observed that the values were in agreement with the experimental data obtained from permeability measurements. In this chapter, simulation has been performed for standard BIIR compound $\left(\mathrm{B}_{100} \mathrm{H}_{0} \mathrm{CB}_{65} \mathrm{NC}_{0}\right)$ and optimized nanocomposite based on BIIR-CO rubber blend $\left(\mathrm{B}_{90} \mathrm{H}_{10} \mathrm{CB}_{50} \mathrm{NC}_{5}\right)$ for air permeability analysis. This is done to understand the structural effects of nanoclay (NC) and $\mathrm{CO}$ rubber on the air permeability of tire inner liner materials. The simulation results were compared to the product results for time-based permeability predictions.

\section{Experimental}

\subsection{Materials}

Bromobutyl rubber (BIIR-2255) was purchased from M/S ExxonMobil Chemical, USA. Polyepichlorohydrin rubber (Hydrin H55) was provided by $\mathrm{M} / \mathrm{S}$ Zeon Chemicals, Louisville KY. Nanoclay (Cloisite 20A) was purchased from M/S Southern Clay Products Inc. Gonzales TX. It contains organic quaternary ammonium ions $\mathrm{N}^{+}\left(\mathrm{CH}_{3}\right)_{2}(\mathrm{HT})_{2}$, where HT represents hydrogenated tallow with approximately $65 \% \mathrm{C}_{18}, 30 \%$ $\mathrm{C}_{16}$ and 5\% $\mathrm{C}_{14}$. Carbon black (GPF N 660 grade) was procured from M/S Philips Carbon Black Limited (PCBL), India. Naphthenic oil (Nytex 810) was supplied by M/S Nynas, Belgium lab. Calcium stearate was supplied by Loba Chemie, India. Zisnet F-PT (2,4,6 trimercapto-sym-triazine), the curing agent for $\mathrm{CO}$ rubber, was provided by $\mathrm{M} / \mathrm{S}$ Zeon Chemicals, Louisville KY. Other compounding ingredients and curing additives were purchased from local suppliers (analytical grade).

\subsection{Preparation of Rubber Blends Nanocomposites}

BIIR and $\mathrm{CO}$ rubbers were melt blended in a Brabender Plasticorder at $55{ }^{\circ} \mathrm{C}$ at a rotor speed of 50 rpm. Preparation of the nanocomposite was divided into two stages for achieving better dispersion of nanoclay in the rubber matrix. The first phase of mixing (master batch) includes melt mixing of BIIR rubber and pre-blended CO-Zisnet F-PT stock (for efficient incorporation of Zisnet chemical in $\mathrm{CO}$ phase), followed by the addition of nanoplatelet (NC/GNP), process aids, carbon black (CB), oil and other functional additives. Nanoplatelet was added at the beginning of the mix to achieve better dispersion in the rubber matrix. The addition of curing agent and accelerators in the second stage of mixing constitutes the final batch. Compounding temperature was set at $55^{\circ} \mathrm{C}$ and the rotor speed was maintained around 50 $\mathrm{rpm}$. The total mixing time for the preparation of the rubber nanocomposites was maintained at 10 minutes. The samples were cured for characterization based on the optimum cure time (OCT) obtained from an oscillating disc rheometer (ODR) at $170{ }^{\circ} \mathrm{C}$. Compounding formulations are tabulated in Table 1.

Table 1 Compound formulation.

\begin{tabular}{lll}
\hline Chemical ingredients & $\mathrm{B}_{100} \mathrm{H}_{0} \mathrm{CB}_{65} \mathrm{NC}_{0}$ & $\mathrm{~B}_{90} \mathrm{H}_{10} \mathrm{CB}_{50} \mathrm{NC}_{5}$ \\
\hline BIIR 2255 & 100 & 90 \\
Hydrin H-55 & - & 10 \\
Stearic acid & 2 & - \\
Calcium stearate & - & 1.5 \\
Process promoter & 15 & 15 \\
CI Resin & 2 & 2 \\
CB N 660 & 65 & 50 \\
Cloisite 20A & - & 5 \\
Cure package & 4.8 & 4.8 \\
\hline
\end{tabular}

\footnotetext{
${ }^{*}$ Cure package consists of ZnO, MBTS, sulphur and PVI.
} 


\section{Characterization}

The samples for HRTEM analysis were carefully made by ultra cryo-microtome using a Leica ultracut. Since the samples are elastomeric in nature, ultramicrotome was performed below the glass transition temperature of the blended rubbers $(-75 \pm$ $5{ }^{\circ} \mathrm{C}$ ) using sharpened glass knives with cutting edge of $45^{\circ}$. Dispersion of nanoclay in the nanocomposites was extensively analyzed by using HRTEM. The cryotomed sections were supported on a copper grid for capturing photomicrographs. The microscopy was performed using JEM-2100, JEOL, Japan.

The FEM simulation of tire inner liner material is performed using ANSYS ${ }^{\circledR}$ software. The decrease in the density of the air with time is measured.

\section{Results and Discussion}

\subsection{Assessment of Nanostructural Morphology}

Dispersion of nanoclay in the $\mathrm{B}_{90} \mathrm{H}_{10} \mathrm{CB}_{50} \mathrm{NC}_{5}$ nanocomposite is analyzed using the HRTEM photomicrographs as shown in Fig. 1. From the figure, it is clear that the nanoclay is well dispersed along the entire matrix. The formation of hybrid nanostructures (NC-CB) exhibits a synergistic interaction between

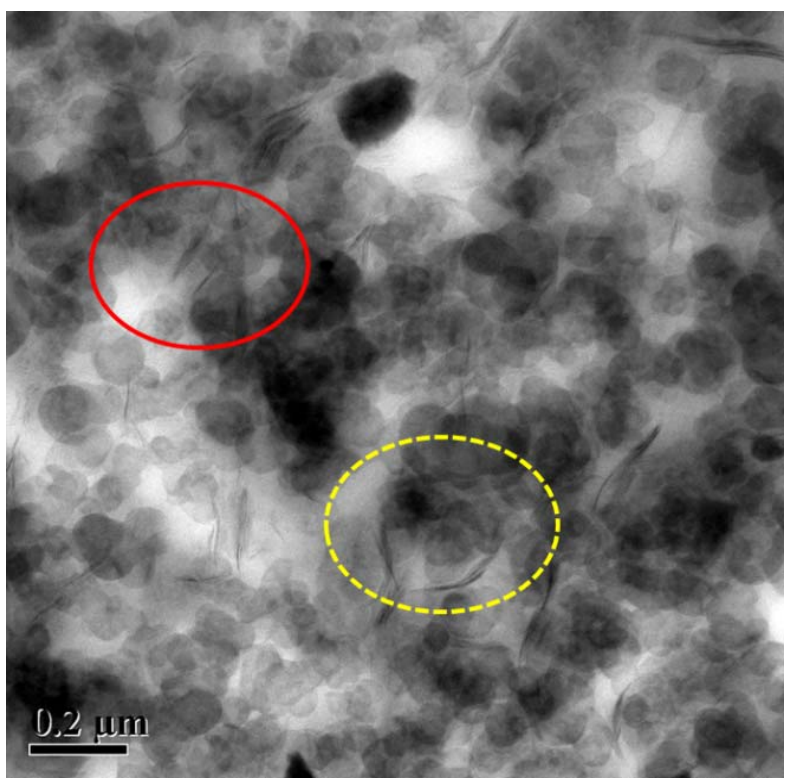

the rubber and filler. It results in the formation of "nanounit", "halo" and "nano-channels" corroborating the overall improvement in filler connectivity [11-15]. The bending of the nanoclay around the carbon black particle (yellow dotted circle in Fig. 1) signifies the development of "nanounit". Just like nanoclay platelets curve around the contours of the carbon black aggregates, the carbon black particles engulf the nanoclay stacks in the nanocomposite. The red circle in the Fig. 1 represents "halo" or haloing effect, in which carbon black particles were surround the nanoclay. It is observed that a synergism is achieved between carbon black and nanoclay due to the formation of such unique "halo" structures. The formations of these nanostructures are frequent in the presence of well dispersed hybrid filler system [16, 17].

\subsection{Finite Element Modeling}

A 2D Cross section of the PCR tire (Tire size: 145/80 R12 tubeless tire) was modeled using the commercial software package ANSYS ${ }^{\circledR}$. The model was meshed with 4-node quadrilateral elements. Based on the mesh convergence study, the element size of $\sim 1$ $\mathrm{mm}$ was used in the present analysis. A thermal analogy

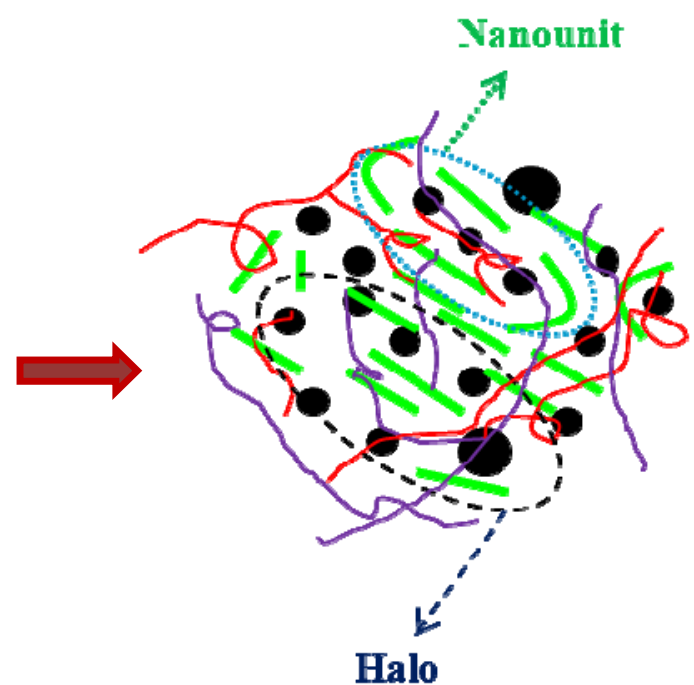

Fig. 1 Hybridization of nanoclay with carbon black to form hybrid nanostructures (nanounit and halo) in $\mathrm{B}_{90} \mathrm{H}_{10} \mathrm{CB}_{50} \mathrm{NC}_{5}$. 
has been adopted to solve the permeability problem for simulation [18]. The rim surface was assumed to have zero thermal diffusion, representing an impermeable layer. For the sake of simplicity, the air permeability of the inner liner of the tire has alone been considered exclusively for simulation. The air permeability of tire inner liner of the tire has been considered typically for simulation. The permeability of air in tire liner based on rubber nanocomposites were typically investigated with time (Fig. 2). The results were compared with the standard compound. The decrease in the density of entrapped air was monitored during the entire transient analysis.

\subsection{Preprocessing}

\subsubsection{Thermal/Permeability Analogy}

The gas permeation process in a medium is governed by the equation:

$$
\partial \mathrm{C} / \partial \mathrm{t}=\mathrm{P}_{\mathrm{M}}\left\{\left(\partial^{2} \mathrm{C} / \partial \mathrm{x}^{2}\right)+\left(\partial^{2} \mathrm{C} / \partial \mathrm{y}^{2}\right)+\left(\partial^{2} \mathrm{C} / \partial \mathrm{z}^{2}\right)\right\}
$$

where, $\mathrm{C}$ is the gas concentration, $\mathrm{P}_{\mathrm{M}}$ is the gas permeability of a medium and $t$ designates time. This equation is in analogous to the heat diffusion (transient heat transfer) equation given by:

$$
\partial \mathrm{T} / \partial \mathrm{t}=\alpha \cdot\left\{\left(\partial^{2} \mathrm{~T} / \partial \mathrm{x}^{2}\right)+\left(\partial^{2} \mathrm{~T} / \partial \mathrm{y}^{2}\right)+\left(\partial^{2} \mathrm{~T} / \partial \mathrm{z}^{2}\right)\right\}
$$

where, $\mathrm{T}$ is the temperature and $\alpha$ is the thermal diffusivity of the system. The thermal diffusivity is written in terms of thermal conductivity $\mathrm{k}$, specific heat $\mathrm{c}$, and density $\rho$ as follows:

$$
\alpha=\{\mathrm{k} /(\rho \cdot \mathrm{c})\}
$$

Assuming that the concentration of the moisture is continuous along the tire inner liner material, a finite element formulation for heat diffusion can be used for gas diffusion problem. A thermal analogy for permeability is represented in Table 2 . The primary variable of the air corresponds to the normalized concentration of air or initial density of the air within the tire. It is calculated by deriving the ideal gas law equation as follows:

$$
\mathrm{PV}=\mathrm{nRT}
$$

where, $\mathrm{P}$ is the pressure of the gas, $\mathrm{V}$ is the volume of the gas, $\mathrm{n}$ is the number of moles, $\mathrm{R}$ is the universal gas constant, and $\mathrm{T}$ is the temperature of the gas. If $\mathrm{C}$ is the concentration of the gas, then the above equation can be written as:

$$
\mathrm{P}=\mathrm{RTC}
$$

The atmospheric pressure of the gas is given as:

$$
\mathrm{P}_{\mathrm{atm}}=\mathrm{RT}_{\mathrm{atm}} \mathrm{C}_{\mathrm{atm}}
$$

The pressure of the air in the tire inner liner (TIL) is given as:

$$
\mathrm{P}_{\mathrm{TIL}}=\mathrm{RT}_{\mathrm{TIL}} \mathrm{C}_{\mathrm{TIL}}
$$

Eq. (6) can be re-arranged as:

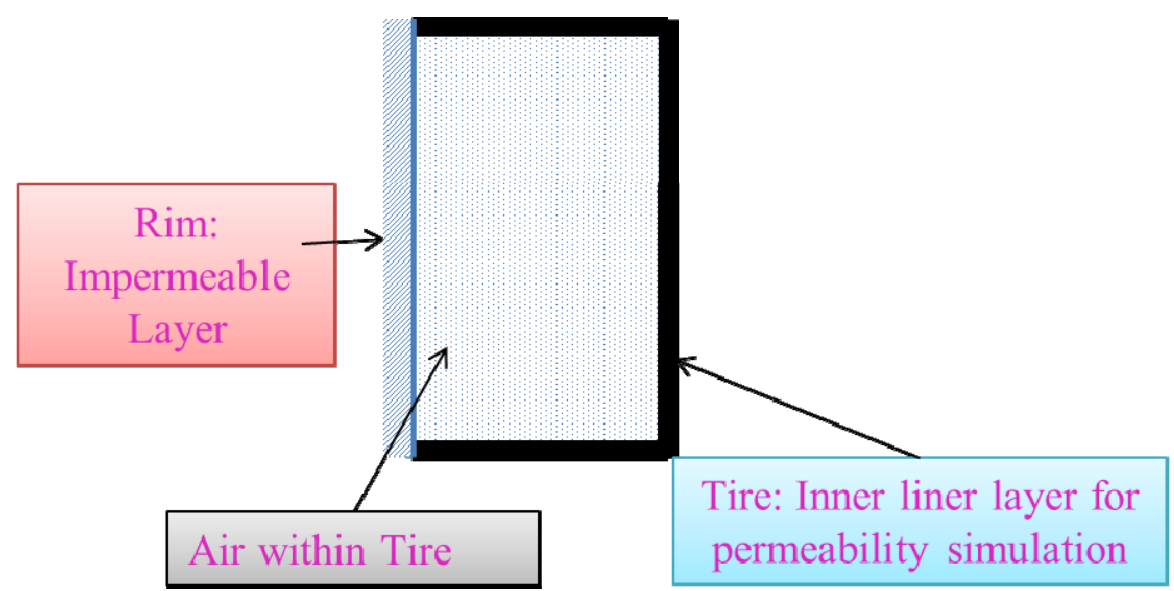

Fig. 2 FEM simulation of air permeability in tire inner liner (cross-sectional view). 
Table 2 Correspondence table for thermal/gas analogy.

\begin{tabular}{lllll}
\hline Property & Thermal & Gas/Air & $\mathrm{B}_{100} \mathrm{H}_{0} \mathrm{CB}_{65} \mathrm{NC}_{0}$ & $\mathrm{~B}_{90} \mathrm{H}_{10} \mathrm{CB}_{50} \mathrm{NC}_{5}$ \\
\hline Primary variable & Temperature, $\mathrm{T}\left({ }^{\circ} \mathrm{C}\right)$ & Normalized Concentration, $\mathrm{C}\left(\mathrm{Kg} / \mathrm{m}^{3}\right)$ & 3.167 & 3.167 \\
Density & $\rho\left(\mathrm{Kg} / \mathrm{m}^{3}\right)$ & 1 & 1 & 1 \\
Conductivity & $k\left(\mathrm{~W} / \mathrm{m} \cdot{ }^{\circ} \mathrm{C}\right)$ & $\mathrm{P}_{\mathrm{M}}$ & 37 & 17 \\
Specific heat & $c\left(\mathrm{~J} / \mathrm{Kg} \cdot{ }^{\circ} \mathrm{C}\right)$ & 1 & 1 & 1 \\
\hline
\end{tabular}

$$
\mathrm{T}_{\mathrm{atm}}=\mathrm{P}_{\mathrm{atm}} / \mathrm{RC}_{\mathrm{atm}}
$$

Eq. (7) can be re-arranged as:

$$
\mathrm{T}_{\mathrm{TIL}}=\mathrm{P}_{\mathrm{TIL}} / \mathrm{RC}_{\mathrm{TIL}}
$$

Assuming $\mathrm{T}_{\mathrm{atm}}=\mathrm{T}_{\mathrm{TIL}}$ initially, following equation is arrived:

$$
\begin{gathered}
\mathrm{P}_{\mathrm{atm}} / \mathrm{C}_{\mathrm{atm}}=\mathrm{P}_{\mathrm{TIL}} / \mathrm{C}_{\mathrm{TIL}} \\
\mathrm{C}_{\mathrm{TIL}}=\mathrm{P}_{\mathrm{TIL}} \times \mathrm{C}_{\mathrm{atm}} / \mathrm{P}_{\mathrm{atm}}
\end{gathered}
$$

Substituting $\mathrm{P}_{\mathrm{TIL}}=2.72$ atm. $\mathrm{P}_{\mathrm{atm}}=1 \mathrm{~atm} . \mathrm{C}_{\mathrm{atm}}=$ $1.1644 \mathrm{~kg} / \mathrm{m}^{3}$ respectively, in Eq. (11), the concentration of the air density in tire inner liner is obtained as follows:

$$
\mathrm{C}_{\mathrm{TIL}}=2.72 \times 1.1644 \mathrm{~kg} / \mathrm{m}^{3}=3.167 \mathrm{~kg} / \mathrm{m}^{3}
$$

Tire inner liner material has been considered typically in the tire modeling. The $3 \mathrm{D}$ view of the tire inner liner of PCR 145/80 R12 tubeless tire is depicted in Fig. 3. The specified tire inner liner dimension was tabulated in Table 3.

\subsubsection{Model Generation}

Based on the thermal analogy and specified dimensions for the modeling, element type and materials properties has been defined. As the permeability is related with thermal conductivity, thermal solid has been selected for the element type and permeability value is assigned to the thermal conductivity. Other thermal properties were shown in Table 2. The meshing area for simulation corresponds to the cross-sectional dimension of the tire inner liner (Table 3 ) and it is depicted in Fig. 4.

\subsection{Solution}

The permeability problem is solved using transient analysis. The initial conditions to define load is based on the TEMP function. The initial value of DOF for TEMP is given as 0 . In the present study, the concentration of air is defined as temperature as the primary variable in thermal analogy. The temperature (normalized gas concentration) boundary condition of the subjected area is applied as 1 for the load TEMP value (black bold line in Fig. 2). The solution was controlled by time based substeps. It constitutes a total of 500 substeps for 5 days with a division of 100 substeps a day.

\subsection{Postprocessing}

\subsubsection{Simulation}

The FE model of the tire inner liner and the enclosed air were depicted clearly in Fig. 5. The thermal contour that relates the density of air in the tire with time is illustrated in Fig. 6.

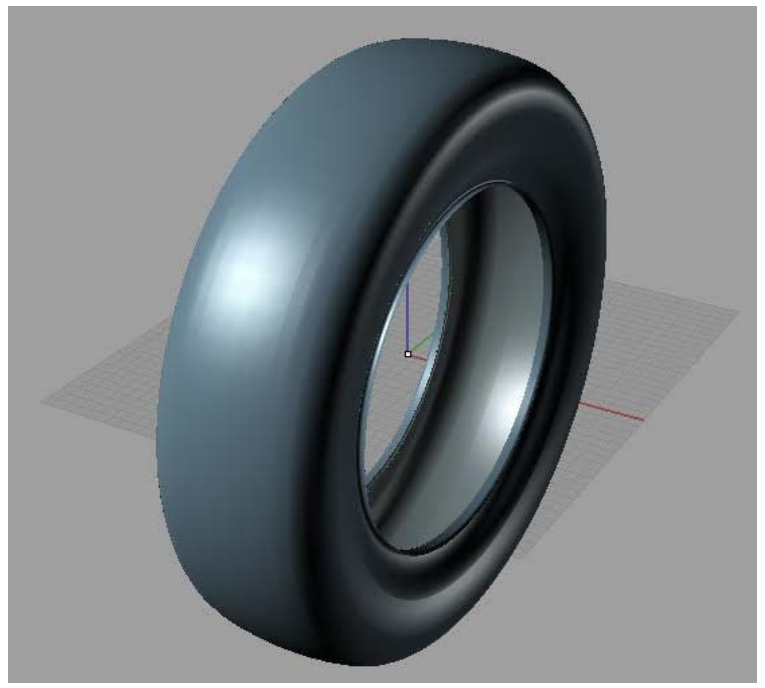

Fig. 3 A 3D view of 145/80 R12 tubeless tire inner liner.

Table 3 Tire inner liner dimensions.

\begin{tabular}{ll}
\hline Dimension $(\mathrm{mm})$ & Values \\
\hline Length & 145 \\
Depth & 116 \\
Thickness & 1 \\
\hline
\end{tabular}




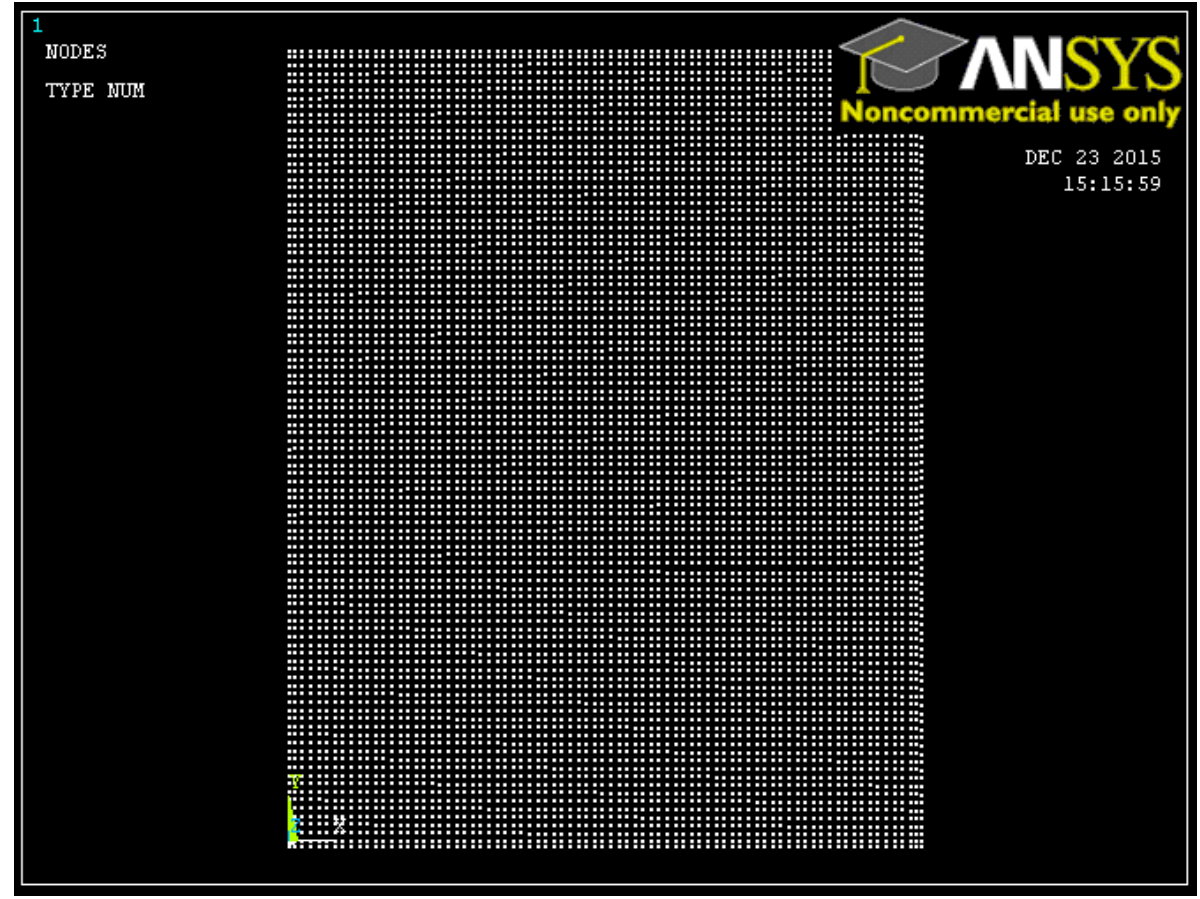

Fig. 4 Meshing area for the permeability simulation.

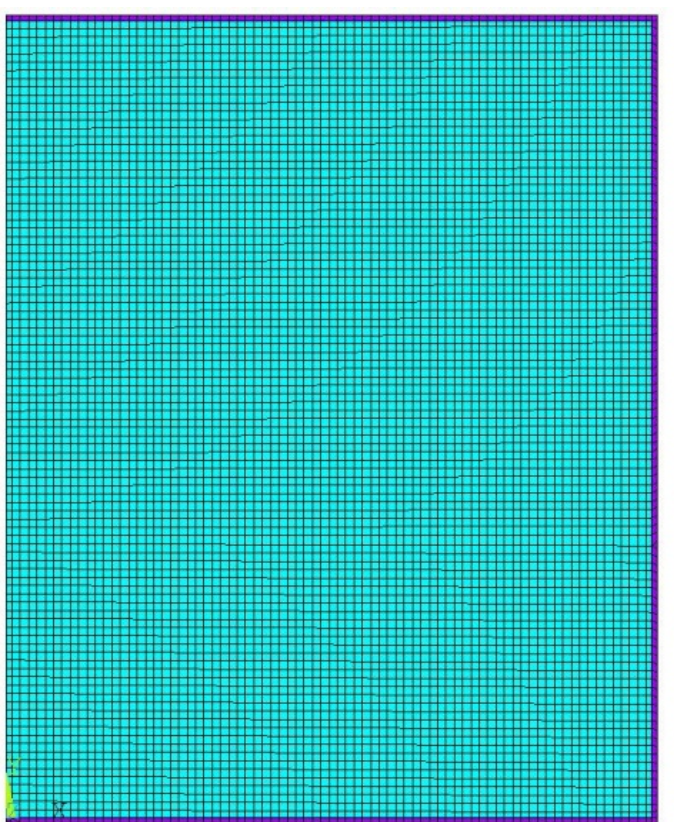

Fig. 5 FE model of the tire inner liner and the enclosed air.

The respective plots for five days run of the samples were shown in Fig. 7. It is observed that the decrement of tire air density is more in BIIR compound to BIIR-CO nanocomposite. The effect is more with the increase in time/days.

It is noticed that the reduction in loss in tire air density (\%) or effective improvement in impermeability of BIIR-CO nanocomposite is up to $17 \%$ compared to the standard BIIR compound (Fig. 8).

\subsubsection{Field Tire Analysis}

To further assess the simulation results, the pressure loss in field tire (PCR 145/80 R12) with time has been monitored experimentally. The efficiency of tire inner liner based on BIIR composite and BIIR-CO nanocomposite has been individually validated. From the Fig. 9, it is found that the permeability or air loss is reduced up to $15 \%$ in BIIR-CO compound $\left(\mathrm{B}_{90} \mathrm{H}_{10} \mathrm{CB}_{50} \mathrm{NC}_{5}\right)$ as compared to that of BIIR compound $\left(\mathrm{B}_{100} \mathrm{H}_{0} \mathrm{CB}_{65} \mathrm{NC}_{0}\right)$. As the analysis is a relative of two tire inner liners, it is to be noted that the effect of other tire constituents on permeability has not been considered for simplicity. However, the improvement of air barrier on tire inner liner based on BIIR-CO nanocomposite reiterates the simulation results.

The input file for calculating the density of air in tire with time is given below:

For BIIR based inner liner composite $\left(B_{100} H_{0} C B_{65} N C_{0}\right)$ : 
Prediction of Air Permeability in Hybrid Nanocomposite Based on Bromobutyl/Epichlorohydrin

Rubber Blends as Tire Inner Liner Using Finite Element Method

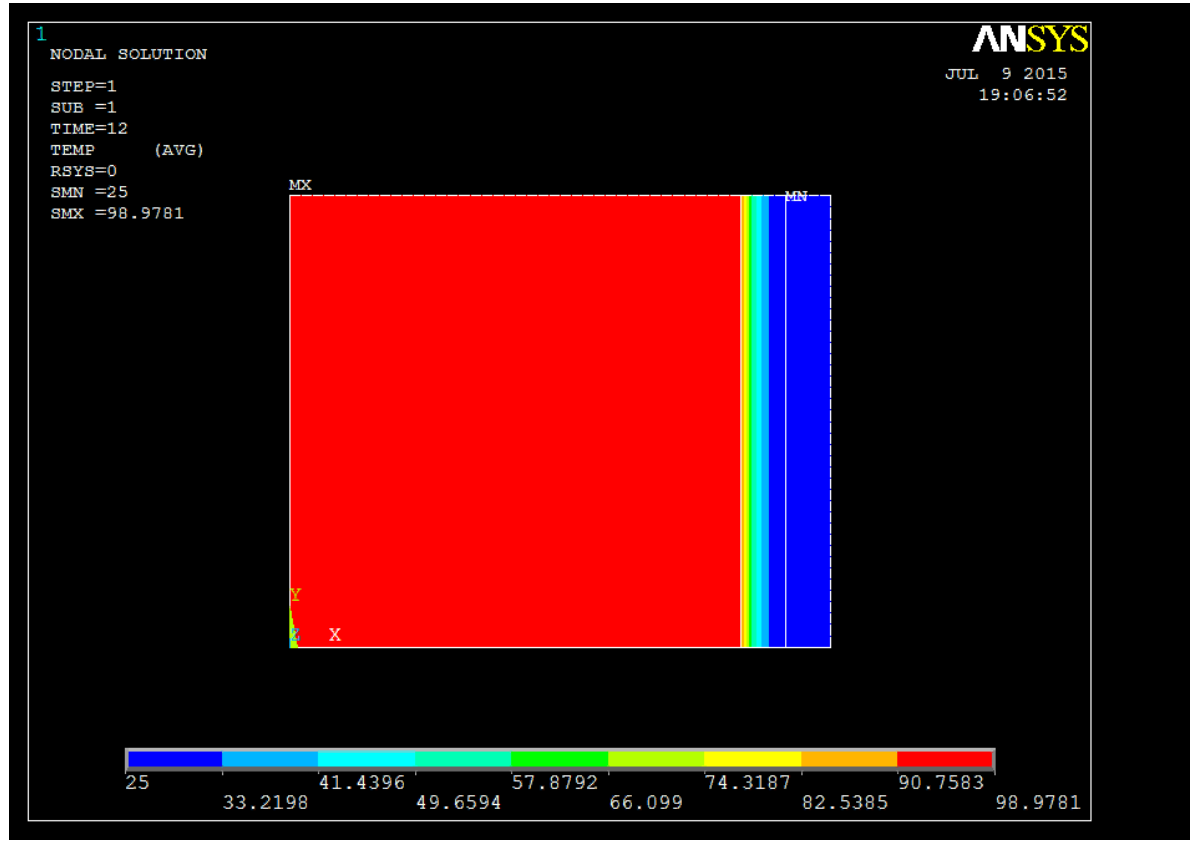

Fig. 6 Contour plot of air permeability (thermal conductivity) in tire inner liner.

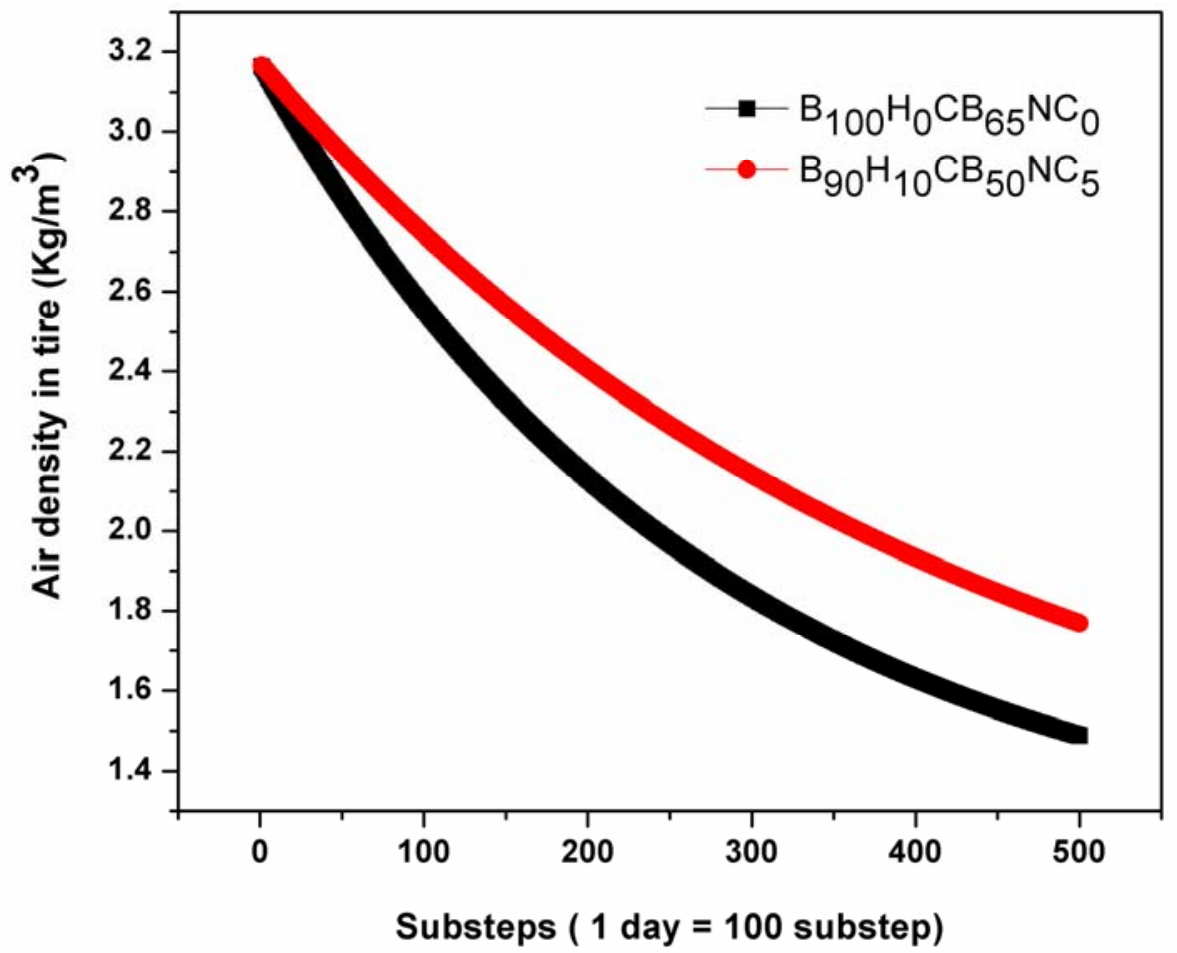

Fig. 7 Density of air in tire vs. days during permeation in samples. 

Rubber Blends as Tire Inner Liner Using Finite Element Method

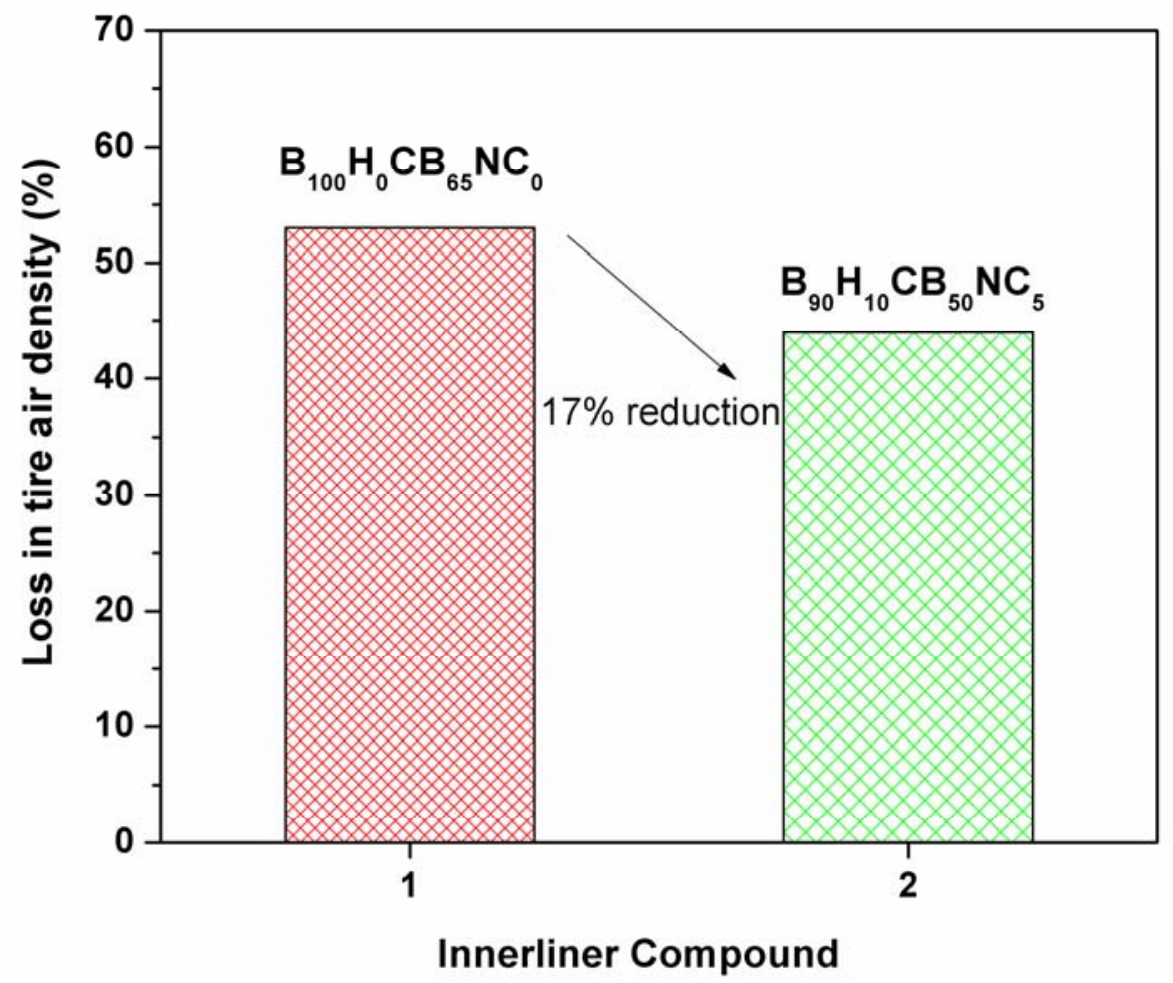

Fig. 8 Loss in tire air density (\%) in standard BIIR compound $\left(\mathrm{B}_{100} \mathrm{H}_{0} \mathrm{CB}_{65} \mathrm{NC}_{0}\right)$ and BIIR-CO nanocomposite $\left(\mathrm{B}_{90} \mathrm{H}_{10} \mathrm{CB}_{50} \mathrm{NC}_{5}\right)$ predicted using FEM simulation.

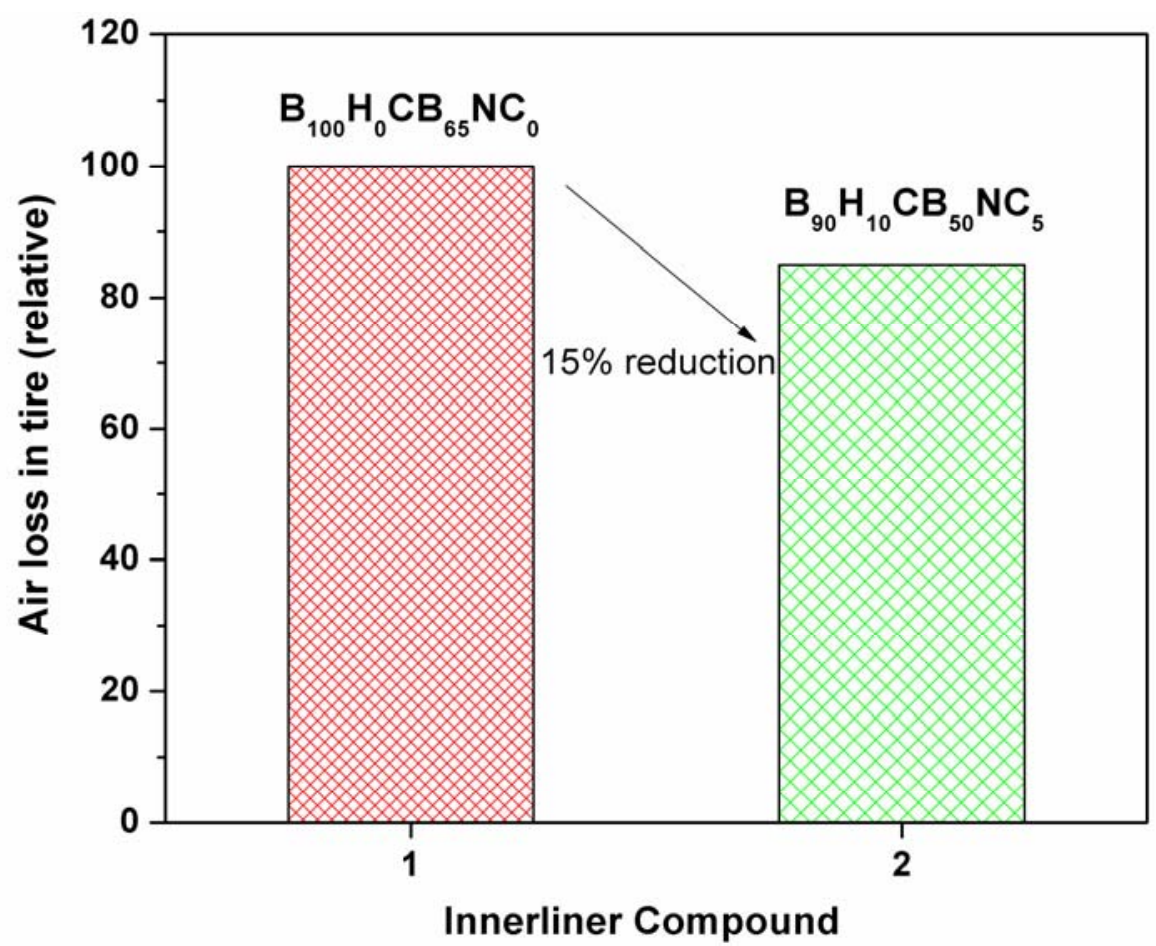

Fig. 9 Air loss in BIIR and BIIR-CO based inner liner composites in PCR145/80 R12 tire after field run test. 


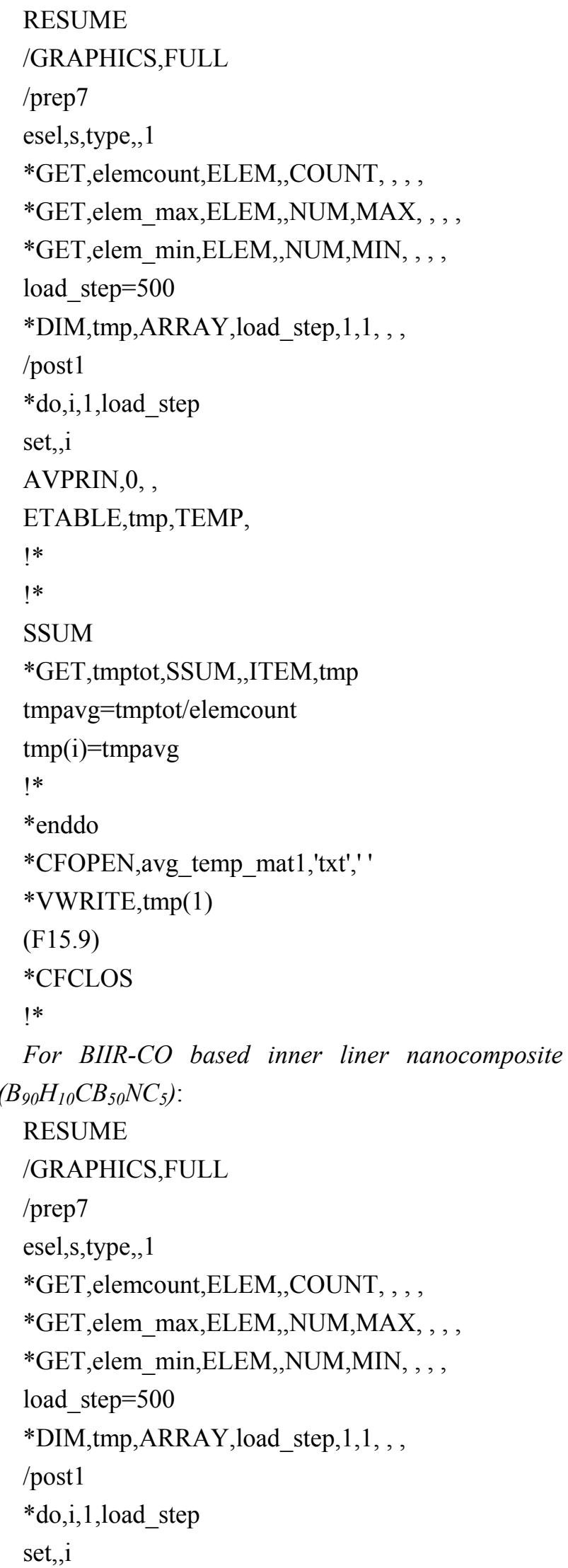

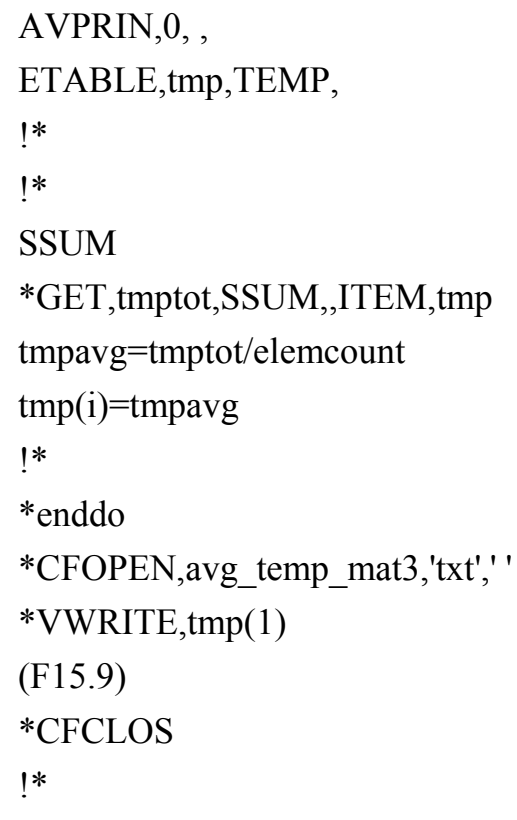

\section{Conclusions}

A successful attempt has been made to simulate, compare, and validate the air permeability in tire inner liner based on BIIR compound and BIIR-CO nanocomposite. ANSYS ${ }^{\circledR}$ software has been adopted effectively for FEM analysis. A novel prediction of time-based gas permeation by employing thermal analogy has been achieved. The density of the air in the tire with time ( 5 days) has been measured as output. Albeit, the permeability of the tire inner liner is only considered in the whole study; the simulation results are validated with field tire experimental results and established. Based on the simulation and experimental results, it is noted that the nanocomposite based on BIIR-CO rubber blend offers a significant improvement in air impermeability (up to $17 \%$ ) as compared to BIIR compound. The findings lead to a unique methodology in predicting the air permeability in the tire which is pivotal in improving the tire durability. The prediction gives a possibility to improve proactively the quality of inner liner compound developed.

\section{Acknowledgement}

The authors acknowledge gratefully the 

Rubber Blends as Tire Inner Liner Using Finite Element Method

management of CEAT LIMITED, Vadodara for funding this work. Special thanks to Mr.C.Cable (Zeon Chemicals, USA) for supplying free samples of $\mathrm{CO}$ rubber and Zisnet F-PT chemicals in this work.

\section{References}

[1] Ashrafi, B. and Hubert, P. 2006. " Modeling the Elastic Properties of Carbon Nanotube Array/Polymer Composites." Compos Sci Technol 66: 387-96.

[2] Haque, A. and Ramasetty, A. 2005. "Theoretical Study of Stress Transfer in Carbon Nanotube Reinforced Polymer Matrix Composites." Compos Struct 71: 68-77.

[3] Cannillo, V., Bondioli, F., Lusvarghi, L., Montorsi, M., Avella, M. and Errico, M. E. et al. 2006. "Modeling of Ceramic Particles Filled Polymer-Matrix Nanocomposites." Compos Sci Technol 66: 1030-7.

[4] Song, Y. S. and Youn, J. R. 2006. "Modeling of Effective Elastic Properties for Polymer Based Carbon Nanotube Composites." Polymer 47: 1741-8.

[5] Zhu, L. and Narh, K. A. 2004. "Numerical Simulation of the Tensile Modulus of Nanoclay- Filled Polymer Composites." J Polym Sci Pol Phys 42: 2391-406.

[6] Hbaieb, K., Wang, Q. X., Chia, Y. H. J. and Cotterell, B. 2007. "Modelling Stiffness of Polymer/Clay Nanocomposites." Polymer 48: 901-9.

[7] Sheng, N., Boyce, M. C., Parks, D. M., Rutledge, G. C., Abes, J. I. and Cohen, R. E. 2004. "Multiscale Micromechanical Modeling of Polymer/Clay Nanocomposites and the Effective Clay Particle." Polymer 45: 487-506.

[8] Dong, Y., Bhattacharyya, D. and Hunter, P. J. 2008. "Experimental Characterisation and Object-Oriented Finite Element Modelling of Polypropylene/Organoclay Nanocomposites." Compos Sci Technol 68: 2864-75.

[9] Chattopadhyay, P. K. 2012. "Epoxidized Natural Rubber based nanocomposites: exploring replacement of carbon black with nanoclay." Ph.D. thesis, Indian Institute of
Technology.

[10] Cerisuelo, J. P., Gavara, R. and Hernández-Muñoz, P. 2015. "Diffusion Modeling in Polymer-Clay Nanocomposites for Food Packaging Applications through Finite Element Analysis of TEM Images." $J$ Membrane Sci 482: 92-102.

[11] Konishi, Y. and Cakmak, M. 2006. "Nanoparticle Induced Network Self-Assembly in Polymer Carbon Black Composites." Polymer 47: 5371-91.

[12] Kumar, S., Nando, G. B., Nair, S., Unnikrishnan, G., Sreejesh, A. and Chattopadhyay, S. 2015. "Analysis of Air Permeability and WVTR Characteristics of Highly Impermeable Novel Rubber Nanocomposite.” Mater Res Express 2: 1-16.

[13] Feller, J. F., Bruzaud, S. and Grohens, Y. 2004. "Influence of Clay Nanofiller on Electrical and Rheological Properties of Conductive Polymer Composite." Mater Lett 58: 739-45.

[14] Chattopadhyay, P. K., Das, N. C. and Chattopadhyay, S. 2011. "Influence of Interfacial Roughness and the Hybrid Filler Microstructures on the Properties of Ternary Elastomeric Composites." Compos Part A-Appl S 42: 1049-59.

[15] Etika, K. C., Liu, L., Hess, L. A. and Grunlan, J. C. 2009. "The Influence of Synergistic Stabilization of Carbon Black and Clay on the Electrical and Mechanical Properties of Epoxy Composites." Carbon 47: 3128-36.

[16] Praveen, S., Chattopadhyay, P. K., Albert, P., Dalvi, V. G., Chakraborty, B. C. and Chattopadhyay, S. 2009. "Synergistic Effect of Carbon Black and Nanoclay Fillers in Styrene Butadiene Rubber Matrix: Development of Dual Structure." Compos Part A-Appl S 40: 309-16.

[17] Bhattacharya, M., Biswas, S. and Bhowmick, A. K. 2011. "Permeation Characteristics and Modeling of Barrier Properties of Multifunctional Rubber Nanocomposites." Polymer 52: 1562-76.

[18] Madenci, E. and Guven, I. 2006. The Finite Element Method and Applications in Engineering Using ANSYS ${ }^{\circledR}$. Springer: New York. 